\title{
Pharyngeal colonisation by Neisseria gonorrhoeae and Neisseria meningitidis in black and white patients attending a venereal disease clinic
}

\author{
ROBERT C. NOBLE, ROBERT M. COOPER, AND BETTY R. MILlER* \\ From the Division of Injectious Diseases, University of Kentucky, College of Medicine, \\ Lexington, Kentucky, USA
}

SUMMARY Pharyngeal colonisation by Neisseria gonorrhoeae and Neisseria meningitidis was studied in 2000 patients attending a venereal disease clinic. Of these patients, $64 \%$ were white and $36 \%$ were black. The incidence of gonococcal infections was highest in the period from June to August. The incidence of genital or rectal infections or both was higher in the black patients. Pharyngeal colonisation by gonococci was present in $1.3 \%$ of the patients. There were no significant associations between pharyngeal colonisation and the pharyngeal symptoms, race, sex, or marital state of the patients. Pharyngeal colonisation was more frequent in patients with gonococcal infections at other sites. However, in $40.7 \%$ of the patients with pharyngeal colonisation, the pharynx was the only culture-positive site. There was no significant difference in the auxotypes or in the antibiotic susceptibility of the pharyngeal and the rectal-genital isolates except in the susceptibility to spectinomycin. Our findings do not indicate that gonococci isolated from the pharynx differ significantly from gonococci isolated from rectal or genital sites. It was notable that meningococcal colonisation of the pharynx was significantly more frequent in the white patients. This may be a genetically determined phenomenon.

\section{Introduction}

Pharyngeal gonococcal infection is recognised as a form of asymptomatic gonorrhoea. It has been described in case studies and in selected groups of patients, such as homosexual men, pregnant women, and patients practising oro-genital intercourse (Fiumara et al., 1967; Owen and Hill, 1972; Pariser, 1972; Rodin et al., 1972; Courman et al., 1974; Wallin, 1974; Shahidullah, 1976; Stutz et al., 1976.) In the present study, pharyngeal culture specimens were taken from consecutive new patients attending a city-county venereal disease clinic. We examined the association of gonococcal pharyngeal colonisation and certain epidemiological variables in a patient population that was known to have a low frequency of oro-genital sexual contact (Noble et al., 1977). Since the meningococcus, another

* In co-operarion with the Lexington-Fayette County Health Department

Address for reprints: Dr Robert C. Noble, Division of Infectious Diseases, Department of Medicine, University of Kentucky College of Medicine, Lexington, Kentucky 40506, USA

Received for publication 5 July 1978 pathogenic Neisseria species, may colonise the same site, the throat cultures were examined for both pathogens by means of selective media. The meningococcal and gonococcal isolates were further examined by serological and microbiological methods to identify sub-populations that might be of epidemiological importance.

\section{Materials and methods}

STUDY POPULATION

The study population consisted of 2000 new patients attending the Lexington-Fayette County Venereal Disease Clinic from September 1975 to October 1976. Samples from the posterior pharynx were taken with sterile cotton-tipped swabs. Culture samples were also taken from the urethra in men and from the cervix and rectum in women. Race, age, sex, and marital state were recorded as part of the patient's routine history.

DIAGNOSTIC METHODS

Samples from the pharynx, genitals, and rectum were immediately streaked on modified Thayer- 
Martin medium containing vancomycin, colistin, nystatin, and trimethoprim (Martin and Lester, 1971) and incubated at $36^{\circ} \mathrm{C}$ for 48 hours. The pharyngeal cultures were incubated in a candle extinction jar, and the genital and rectal cultures were incubated in an atmosphere containing $\mathrm{CO}_{2}$. Patients with gonorrhoea were defined as those men having Gram-negative intracellular diplococci present in a urethral smear or those patients of either sex who had positive culture results on modified Thayer-Martin medium of an oxidase-positive ( $1 \%$ solution of $\mathrm{N}$ - $\mathrm{N}$-dimethyl-p-phenylene-diamine monohydrochloride), Gram-negative diplococcus. The rectal-genital cultures used in this study were randomly selected from different patients attending the venereal disease clinic during the year of the study. The selection was performed so that the proportion of black and white patients in the rectal-genital group would be the same as in the pharyngeal group.

All pharyngeal and selected genital cultures were identified by bacterial morphology, Gram stain, oxidase reaction, and production of acid with one or more of the following sugars: glucose, maltose, lactose, sucrose, or fructose. The latter medium contained $1 \%$ of the test carbohydrate in cystine tryptic agar (Difco, Detroit, Michigan). GC medium base (Difco) with $1 \%$ IsovitaleX supplement (Baltimore Biological Laboratories, Cockeysville, Maryland) was used as the culture medium for bacterial isolation. Meningococcal serogrouping was performed by a slide agglutination technique (Feldman, 1970) with antisera (supplied by the US Center for Disease Control) for serogroups A, B, C, D, X, Y, and Z. The following meningococci (from the American Type Culture Collection) were used as reference standards: Neisseria meningitidis serogroup A, ATCC 13077; serogroup B, ATCC 13090; serogroup C, ATCC 13102; and serogroup D, ATCC 13113. Meningococcal and gonococcal isolates were stored at $-70^{\circ}$ in tryptic soy broth (Difco) containing $13 \%$ glycerol.

\section{AUXOTYPING OF GONOCOCCI}

Isolates from the pharynx and selected genital isolates of Neisseria gonorrhoeae were auxotyped by the method of Catlin (1973). Auxotyping was performed twice on each isolate and gonococci of known auxotype were included as controls.

\section{ANTIBIOTIC SENSITIVITY-TESTING OF} GONOCOCCI

Antibiotic sensitivity-testing was performed by means of a plate dilution technique (Jaffe et al., 1976). Duplicate inocula were made with a Steers replicator (Steers et al., 1959). Strains of $N$. gonorrhoeae (F18 and F29) and Sarcina lutea (F20) (supplied by the US Center for Disease Control) with known antibiotic susceptibilities were included as controls when gonococcal isolates were tested for their antibiotic susceptibilities. The antibiotics (US Pharmacopeial Convention Inc., Bethesda, Maryland) were tested in the following concentrations by means of twofold dilution in agar: penicillin $(2-0.008 \mu \mathrm{g} / \mathrm{ml})$; ampicillin $(2-0.008 \mu \mathrm{g} / \mathrm{ml})$; spectinomycin $(100-0.39 \mu \mathrm{g} / \mathrm{ml})$; and tetracycline $(25-0 \cdot 1 \mu \mathrm{g} / \mathrm{ml})$.

\section{STATISTICAL METHODS}

Yates's $\chi^{2}$ tests were used for categorical data, and the Mann-Whitney $U$ test (two-tailed) was used in the analysis of the antibiotic sensitivity data.

\section{Results}

PATIENT POPULATION

Of the $64 \%$ of white patients and the $36 \%$ of black $60 \%$ were men and $40 \%$ were women in both racial groups; $77 \%$ were single, $11 \%$ married, and $9 \%$ divorced or separated. Their mean age was 20 years. Gonococcal infection of the cervix or rectum was present in $25 \%$ of the women and urethral infection was present in $30 \%$ of the men. Urethral infections were more common in black men $(47.1 \%)$ than in white men $(21.0 \%)\left(\chi_{1}{ }^{2}=86.93, \mathrm{P}<0.001\right)$. Cervical and rectal infections were more common in black women $(35.2 \%)$ than in white women $(19.0 \%)$ $\left(\chi_{1}^{2}=24 \cdot 7, \mathrm{P}<0.001\right)$.

\section{PHARYNGEAL GONOCOCCAL}

\section{COLONISATION}

$N$. gonorrhoeae was isolated from the pharynx in $1.3 \%(27 / 2000)$ of the patients. None of the patients complained of a sore throat. Of the 27 patients with positive pharyngeal culture results for $N$. gonorrhoeae, 15 were white and six were black men, and three were white and three were black women. Pharyngeal gonococcal colonisation occurred with similar frequency in black $(1.2 \%)$ and white $(1.5 \%)$ patients. Although pharyngeal gonococcal colonisation was more than twice as common in men $(1.8 \%)$ than in women $(0.7 \%)$ this difference was not statistically significant. Pharyngeal colonisation was more common in patients with gonococci isolated from other sites, $(2.8 \%, 16 / 570)$ than in patients who were otherwise free of gonococci $(0.8 \%, 11 / 1430)\left(\chi_{1}^{2}=11 \cdot 22, P<0.001\right)$. In patients with concurrent genital or rectal gonorrhoea, $3 \cdot 3 \%$ $(12 / 363)$ of the men and $1.9 \%(4 / 207)$ of the women had pharyngeal gonococcal colonisation. The pharynx was the only culture-positive site in $1.9 \%$ of 
patients with gonorrhoea. Nine out of 21 men with pharyngeal gonorrhoea had negative urethral culture results, and two of six women with pharyngeal gonorrhoea had negative cervical and rectal culture results. Thus, in $40.7 \%(11 / 27)$ of patients with pharyngeal gonorrhoea, the pharynx was the only culture-positive site. Nineteen out of 21 men with pharyngeal gonorrhoea were asked about their sexual habits; only three stated that they were homosexual. Table 1 shows that during the study period the incidence of gonorrhoea was highest during the three months June to August $\left(\chi_{9}{ }^{2}=27.08\right.$, $\mathbf{P}<0.01$ ). Gonococci were also more frequently isolated in pharyngeal cultures from patients during this period, and the increased frequency paralleled the increase in gonococcal isolates from genital and rectal sites.

Six different auxotypes were present among 26 of the pharyngeal isolates. One isolate became nonviable before auxotyping. The auxotypes of the pharyngeal isolates were compared with the auxotypes of 150 randomly picked rectal or genital isolates from different patients attending the venereal disease clinic during the year of the study.
The rectal-genital isolates were selected to represent the same proportion of black and white patients as were present in the pharyngeal group. Table 2 indicates no significant difference in the distribution of the auxotypes in the pharyngeal compared with the rectal-genital group. The pharyngeal and genital isolates were tested for their susceptıbility to four antibiotics: penicillin, ampicillin, tetracycline, and spectinomycin. Of the antibiotics tested only the susceptibility to spectinomycin differed significantly between the two groups. As shown in Table 3, the pharyngeal isolates were more susceptible to spectinomycin than were the rectalgenital isolates.

\section{PHARYNGEAL MENINGOCOCCAL COLONISATION}

Meningococci were cultured from the pharynx in $9.5 \%$ of the patients. Meningococcal colonisation was more common in white $(13.5 \%)$ than in black $(2.3 \%)$ patients $\left(\chi_{1}{ }^{2}=65.8, \mathrm{P}<0.001\right)$. Meningococcal colonisation was present in $15.3 \%$ of white men and in $12.4 \%$ of white women $\left(\chi_{1}{ }^{2}=4 \cdot 37\right.$, $\mathbf{P}<0.05)$ compared with $2.4 \%$ of black men and

Table 1 Seasonal variation in percentage of patients with gonococcal infections

\begin{tabular}{|c|c|c|c|c|c|}
\hline \multirow[b]{2}{*}{ Infected site } & \multicolumn{5}{|l|}{ Months } \\
\hline & $\begin{array}{l}\text { Dec-Feb* } \\
(\%)\end{array}$ & $\begin{array}{l}\text { Mar-May* } \\
(\%)\end{array}$ & $\begin{array}{l}\text { June-Aug* } \\
(\%)\end{array}$ & $\begin{array}{l}\text { Sep-Nov* } \\
(\%)\end{array}$ & $\begin{array}{l}\text { Total } \\
\text { numbers }\end{array}$ \\
\hline Pharynx only & $18 \cdot 2$ & $9 \cdot 1$ & $45 \cdot 4$ & $27 \cdot 3$ & 11 \\
\hline $\begin{array}{l}\text { Pharynx plus rectum or genitals or } \\
\text { both } \\
\text { Rectum or genitals or both } \\
\text { Patients attending the clinic }(\%)\end{array}$ & $\begin{array}{r}6 \cdot 2 \\
20 \cdot 8 \\
23 \cdot 3\end{array}$ & $\begin{array}{r}6 \cdot 2 \\
16 \cdot 2 \\
14 \cdot 6\end{array}$ & $\begin{array}{l}68 \cdot 8 \\
37 \cdot 5 \\
32 \cdot 3\end{array}$ & $\begin{array}{l}18 \cdot 8 \\
25 \cdot 4 \\
29 \cdot 7\end{array}$ & $\begin{array}{r}16 \\
554 \\
1997\end{array}$ \\
\hline
\end{tabular}

$\chi_{9}^{2}=27.08, P<0.01$

*Percentage of total

Table 2 Comparison of auxotypes of Neisseria gonorrhoeae from pharyngeal and rectal-genital sources

\begin{tabular}{|c|c|c|c|c|c|c|}
\hline \multirow[b]{2}{*}{ Site } & \multicolumn{6}{|c|}{ Auxotypes } \\
\hline & $\begin{array}{l}\text { Zero } \\
(\%)\end{array}$ & $\begin{array}{l}\text { Pro. } \\
(\%)\end{array}$ & $\begin{array}{l}\text { Arg. } \\
(\%)\end{array}$ & $\begin{array}{l}A H U \\
(\%)\end{array}$ & $\begin{array}{l}\text { Other } \\
(\%)\end{array}$ & $\begin{array}{c}\text { Total } \\
\text { number }\end{array}$ \\
\hline $\begin{array}{l}\text { Pharynx } \\
\text { Rectum/genitals }\end{array}$ & $\begin{array}{l}30 \cdot 8 \\
25 \cdot 3\end{array}$ & $\begin{array}{l}42 \cdot 3 \\
39 \cdot 3\end{array}$ & $\begin{array}{l}7 \cdot 7 \\
8 \cdot 0\end{array}$ & $\begin{array}{l}15 \cdot 4 \\
22 \cdot 7\end{array}$ & $\begin{array}{l}3 \cdot 8 \\
4 \cdot 6\end{array}$ & $\begin{array}{r}26 \\
150\end{array}$ \\
\hline
\end{tabular}

$\chi_{4}{ }^{2}=4 \cdot 46, P<0.5$

Table 3 Spectinomycin sensitivities of pharyngeal and rectal-genital isolates of Neisseria gonorrhoeae ( $\%$ )

\begin{tabular}{|c|c|c|c|c|c|c|c|c|}
\hline \multirow[b]{2}{*}{ Site } & \multicolumn{7}{|c|}{ Spectinomycin $(\mu \mathrm{g} / \mathrm{ml})$} & \multirow[b]{2}{*}{ Total number } \\
\hline & 25 & $12 \cdot 5$ & $6 \cdot 25$ & $3 \cdot 12$ & $1 \cdot 56$ & 0.78 & 0.39 & \\
\hline $\begin{array}{l}\text { Pharynx } \\
\text { Rectum/genitals }\end{array}$ & $\begin{array}{r}0 \\
1.4\end{array}$ & $\begin{array}{l}33 \cdot 3 \\
52 \cdot 5\end{array}$ & $\begin{array}{l}33 \cdot 3 \\
25 \cdot 2\end{array}$ & $\begin{array}{l}12 \cdot 5 \\
13 \cdot 7\end{array}$ & $\begin{array}{r}12 \cdot 5 \\
4 \cdot 3\end{array}$ & $\begin{array}{l}8 \cdot 3 \\
1 \cdot 4\end{array}$ & $\begin{array}{r}0 \\
1 \cdot 4\end{array}$ & $\begin{array}{r}24 \\
139\end{array}$ \\
\hline
\end{tabular}

$Z=2 \cdot 057, P=0.0202$ (Mann-Whitney $U$ test) 
$2.5 \%$ of black women. Meningococcal colonisation was not associated with marital state and no significant seasonal variation in incidence was noted. Meningococci were concurrently isolated from only two of the 27 patients who were colonised with gonococci in the pharynx. Meningococcal colonisation was also not associated with the presence of rectal or genital gonococcal infection. Of the 189 meningococcal isolates 148 were available for serogrouping; of these, $26 \%$ were autoagglutinable and $19 \%$ could not be grouped (Table 4 ).

OTHER NEISSERIA SPECIES

Sixteen isolates of other Neisseria species were identified in the pharyngeal cultures; nine $(0.4 \%)$ were $N$. lactamica, five $(0.2 \%) N$. flavescens, and two $(0.1 \%) N$. subflava. None was isolated in association with gonococci or meningococci.

\section{Discussion}

The results of our study are compared with those of previous surveys of gonococcal pharyngeal colonisation in patients attending venereal disease clinics in the United States and other countries in Table 5. In contrast to the other studies, pharyngeal colonisation by gonococci in our patients was more common in men than in women. This difference might have been explained if there had been a large number of homosexual men among the clinic patients (Wiesner et al., 1973). However, the majority of men with positive pharyngeal culture results said that they were heterosexual, and case histories from these men suggested that the most likely route of infection was by oro-genital sexual contact. Pharyngeal colonisation by gonococci was equally frequent in patients of both races. This finding was unexpected since oro-genital with penile-vaginal sexual contact in patients from this clinic was previously shown to be significantly more frequent among white patients than black $-17 \%$ of white women compared with $4 \%$ of black women and $17 \%$ of white men compared with $2 \%$ of black men (Noble et al., 1977). Although histories of sexual contact were not obtained from all patients in the present study, the higher pharyngeal colonisation rate in men may be a reflection of the higher incidence of genital infection in men and of the predominance of white men in the clinic population.

Although an association between race and disease may be confounded with socioeconomic variables, black individuals may be more susceptible to the gonococcus and thus have a higher incidence of infection following exposure. Such a susceptibility could be mediated by a genetically determined biological mechanism. The present and other studies (Noble et al., 1977; Brooks et al., 1978) have shown that genital or rectal gonorrhoea is more common among black than white clinic patients. The present study also showed a marked difference in meningococcal colonisation of the pharynx in black patients compared with white. Race, as a factor in meningococcal colonisation, has not been extensively studied except in military recruits and

Table 4 Distribution by race of meningococcal serogroups isolated from clinic patients ( $\%)$

\begin{tabular}{|c|c|c|c|c|c|c|c|c|c|c|}
\hline \multirow[b]{2}{*}{ Race } & \multicolumn{9}{|c|}{ Serogroup } & \multirow[b]{2}{*}{ Total number } \\
\hline & $A$ & $B$ & $C$ & $D$ & $X$ & $Y$ & $Z$ & Autoagglutinated & Non-groupable & \\
\hline $\begin{array}{l}\text { White } \\
\text { Black }\end{array}$ & $\begin{array}{r}4 \cdot 4 \\
16 \cdot 7\end{array}$ & $\begin{array}{l}18 \cdot 4 \\
33 \cdot 3\end{array}$ & $\begin{array}{r}6.6 \\
0\end{array}$ & $\begin{array}{l}0 \\
0\end{array}$ & $\begin{array}{r}2 \cdot 9 \\
0\end{array}$ & $\begin{array}{r}14 \cdot 7 \\
8 \cdot 3\end{array}$ & $\begin{array}{r}6.6 \\
0\end{array}$ & $\begin{array}{l}27 \cdot 2 \\
16 \cdot 7\end{array}$ & $\begin{array}{l}19 \cdot 1 \\
25 \cdot 0\end{array}$ & $\begin{array}{r}136 \\
12\end{array}$ \\
\hline
\end{tabular}

Table 5 Studies of gonococcal pharyngeal colonisation $(G P C)$ in venereal disease clinic patients with gonorrhoea

\begin{tabular}{|c|c|c|c|c|c|c|c|}
\hline \multirow[t]{2}{*}{ Author } & \multirow[t]{2}{*}{ Date } & \multirow[t]{2}{*}{ Country of study } & \multirow{2}{*}{$\begin{array}{l}\text { Total number of } \\
\text { patients with } \\
\text { gonorrhoea }\end{array}$} & \multicolumn{2}{|c|}{$\%$ with pharyngeal colonisation } & \multirow{2}{*}{$\begin{array}{l}\% \text { of patients } \\
\text { with GPC with } \\
\text { pharynx as only } \\
\text { positive site }\end{array}$} & \multirow[t]{2}{*}{$\begin{array}{l}\% \text { of } G P C \text { in } \\
\text { clinic population }\end{array}$} \\
\hline & & & & Men & Women & & \\
\hline $\begin{array}{l}\text { Bro-Jørgensen and } \\
\text { Jensen } \\
\text { Weisner et al. } \\
\text { Bro-Jørgensen and }\end{array}$ & $\begin{array}{l}1971 \\
1973\end{array}$ & $\begin{array}{l}\text { Denmark } \\
\text { USA (Seattle) }\end{array}$ & $\begin{array}{l}161 \\
405\end{array}$ & $\begin{array}{l}6 \\
3 \cdot 2\end{array}$ & $\begin{array}{r}9 \cdot 1 \\
10 \cdot 3\end{array}$ & $\begin{array}{l}0 \\
4 \cdot 2\end{array}$ & $\begin{array}{l}2 \cdot 8 \\
5 \cdot 6\end{array}$ \\
\hline $\begin{array}{l}\text { Jensen } \\
\text { Odegaard and }\end{array}$ & 1973 & Denmark & 1104 & $7 \cdot 0$ & $10 \cdot 0$ & $14 \cdot 5$ & $?$ \\
\hline $\begin{array}{l}\text { Gundersen } \\
\text { Stolz and Schuller } \\
\text { Hallqvist and Lindgren } \\
\text { Newnham et al. } \\
\text { Noble et al. }\end{array}$ & $\begin{array}{l}1973 \\
1974 \\
1975 \\
1975\end{array}$ & $\begin{array}{l}\text { Norway } \\
\text { Netherlands } \\
\text { Sweden } \\
\text { Australia }\end{array}$ & $\begin{array}{r}1440 \\
1133 \\
3271 \\
122\end{array}$ & $\begin{array}{l}5 \cdot 0 \\
3 \cdot 6 \\
3 \cdot 6 \\
6 \cdot 2\end{array}$ & $\begin{array}{r}11 \cdot 3 \\
8 \cdot 4 \\
5 \cdot 8 \\
11 \cdot 1\end{array}$ & $\begin{array}{r}16 \cdot 0 \\
3 \cdot 3 \\
1 \cdot 1 \\
36 \cdot 0\end{array}$ & $\begin{array}{l}2 \cdot 9 \\
1 \cdot 6 \\
? \\
1 \cdot 1\end{array}$ \\
\hline (present study) & 1979 & USA (Lexington) & 575 & $5 \cdot 6$ & $2 \cdot 9$ & $40 \cdot 7$ & $1 \cdot 3$ \\
\hline
\end{tabular}


servicemen undergoing training. In one study, a small subgroup of black servicemen had positive meningococcal pharyngeal culture results in proportion to their numbers in the group (Farrell and Dahl, 1966). In another study, Polynesian soldiers had higher meningococcal colonisation rates than did European soldiers (Knights, 1972). However, meningococcal acquisition and colonisation among military recruits may be higher than in the general population. Our findings of a low meningococcal colonisation rate in black patients might be explained if they acquired meningococcal infections at an earlier age with a resulting immunity as adults. However, the incidence of meningococcal meningitis is the same or slightly higher among white compared with black children, whereas the incidence of pneumococcal and haemophilus meningitis is higher in black children (Fraser et al., 1973; Floyd et al., 1974). Racial differences have been described in the pharyngeal colonisation of another pathogenic micro-organism. Pharyngeal colonisation by Staphylococcus aureus but not $\beta$-haemolytic streptococci is significantly more common in white than in black patients (Noble, 1974). Unfortunately, the small number of meningococcal isolates from black patients in our clinic was inadequate to correlate the meningococcal serogroups with the patients' race. Thus, it is unknown if certain meningococcal serogroups are found more frequently in white compared with black individuals. Although this and other studies have shown a slightly higher colonisation rate in men than in women (Greenfield et al., 1971), the acquisition rate of meningococcal pharyngeal colonisation is the same with respect to sex in military recruits (Melton et al., 1977).

Willcox et al. (1977) obtained pharyngeal cultures from patients attending a venereal disease clinic and found that patients harbouring meningococci in the pharynx were more likely to have genital gonococci than those who were not carrying meningococci. We were unable to identify an association between pharyngeal meningococcal colonisation and genital infection with gonococci. The difference in the two studies may lie in the fact that in the present study all new clinic patients had culture specimens taken whereas in their study only selected patient groups had specimens taken for culture.

Gonococci isolated from the pharynx and from a second site in the same patient usually have identical antibiotic sensitivities (Bro-Jørgensen and Jensen, 1973; Stolz and Schuller, 1974; Hallqvist and Lindgren, 1975; Catlin and Pace, 1977a). However, pharyngeal isolates have been reported to be more resistant to ampicillin and penicillin (Ödegaard and Gundersen, 1973; Hallqvist and Lindgren, 1975; Catlin and Pace, 1977b) and to have different auxotypes (Catlin and Pace, 1977b) when compared with genital isolates from other patients. Gonococcal strains requiring arginine, hypoxanthine, and uracil are more susceptible to penicillin $\mathbf{G}$ (Knapp and Holmes, 1975), and they are isolated more frequently from white patients (Crawford et al., 1977). Thus, when gonococci from the pharynx are compared with gonococci isolated from other sites the race of the infected patient is a significant variable. In the present study the number of white and black patients was proportional in both groups and no significant difference was observed in the auxotype or in the susceptibility to the antibiotics, penicillin, ampicillin, or tetracycline. However, the pharyngeal isolates were more susceptible to spectinomycin than were the rectal-genital isolates. This finding is unexplained and is of no clinical value since spectinomycin is relatively ineffective in the treatment of pharyngeal gonococcal infections (Wiesner et al., 1973). Thus, with this exception, our findings indicate no significant differences in isolates from the pharynx compared with isolates from rectal or genital sites.

The pharynx was the only culture-positive site in two-fifths of our patients with gonococcal pharyngeal colonisation. This represents less than $1 \%$ of cultures from all patients and less than $2 \%$ of cultures from all clinic patients with gonorrhoea. Therefore, the relatively low incidence of pharyngeal gonococcal infection coupled with the difficulty of performing large numbers of sugar fermentation reactions on pharyngeal isolates argues against the routine screening of all patients for gonococcal pharyngeal colonisation. The effectiveness of alternative diagnostic techniques should be evaluated to limit the number of cultures required and also to establish the consequences of untreated pharyngeal colonisation with gonococci. The finding of an increased incidence of meningococcal colonisation in white patients may indicate differences in genetically determined mucosal receptor sites in the pharynx and merits further study.

The authors gratefully acknowledge the co-operation of Dr Philip G. Weiler, Commissioner of Health, Lexington-Fayette County Health Department, and the staff of the Venereal Disease Clinic of the Health Department. We also thank Dr G. W. Somes, Department of Community Medicine, for his help in the statistical analysis.

The meningococcus grouping antisera were donated by $\mathrm{Dr}$ W. K. Harrell of the Biologic Reagents Section, US Center for Disease Control, Atlanta, Georgia, and Dr Max D. Moody, Technical 
Director, Burroughs-Wellcome Co., Research Triangel Park, North Carolina. Strains of Neisseria gonorrhoeae (F18 and F29) and Sarcina lutea (F20) were provided by Dr Clyde Thornsberry, US Center for Disease Control.

Funds for this study were provided in part by research grant AI 11304 from the National Institute of Allergy and Infectious Disease and a grant from the Alexandrine and Alexander Sinsheimer Fund.

\section{References}

Bro-Jørgensen, A., and Jensen, T. (1971). Gonococcal tonsillar infections. British Medical Journal, 2, 660-661.

Bro-Jørgensen, A., and Jensen, T. (1973). Gonococcal pharyngeal infections : Report of 110 cases. British Journal of Venereal Diseases, 49, 491-499.

Brooks, G. F., Darrow, W. W., and Day, J. A. (1978). Repeated gonorrhea: An analysis of importance and risk factors. Journal of Infectious Diseases, 137, 161-169.

Catlin, B. W. (1973). Nutritional profiles of Neisseria gonorrhoeae, Neisseria meningitidis, and Neisseria lactamica in chemically defined media and the use of growth requirements for gonococcal typing. Journal of Infectious Diseases, 128, 178-193.

Catlin, B. W., and Pace, P. J. (1977a). Auxotypes and penicillin susceptibilities of Neisseria gonorrhoeae isolated from patients with gonorrhea involving two or more sites. Antimicrobial Agents and Chemotherapy, 12, 147-156.

Catlin, B. W., and Pace, P. J. (1977b). Nutritional requirements and penicillin susceptibilities of gonococci from pharyngeal and anogenital sites. British Journal of Venereal Diseases, 53, 299-303.

Courman, L. C., Levison, M. E., Knight, R., Carrington, E. R., and Kaye, D. (1974). The high frequency of pharyngeal gonococcal infection in a prenatal clinic population. Journal of the American Medical Association, 230, 568-570.

Crawford, G., Knapp, J. S., Hale, J., and Holmes, K. K. (1977). Asymptomatic gonorrhea in men caused by gonococci of unique nutritional requirements. Science, 196, 1352-1343.

Farrell, D. G., and Dahl, E. V. (1966). Nasopharyngeal carriers of Neisseria meningitidis. Journal of the American Medical Association, 198, 167-170.

Feldman, H. A. (1970). Neisseria infections other than gonococcal. In Diagnostic Procedures for Bacterial, Mycotic and Parasitic Infection, Chapter VIII, fifth edition. Edited by H. L. Bodily, E. L. Updyke, and J. O. Mason. American Public Health Association.

Fiumara, N. J., Wise, H. M., and Many, M. (1967). Gonococcal pharyngitis. New England Journal of Medicine, 276, 1248-1250.

Floyd, R. F., Federspiel, C. F., and Schaffner, W. (1974). Bacterial meningitis in urban and rural Tennessee. American Journal of Epidemiology, 99, 395-407.

Fraser, D. W., Darby, C. P., Koehler, R. E., Jacobs, C. F., and Feldman, R. A. (1973). Risk factors in bacterial meningitis: Charleston county, South Carolina. Journal of Infectious Diseases, 127, 271-277.

Greenfield, S., Sheehe, P. R., and Feldman, H. A. (1971). Meningococcal carriage in a population of normal families. Journal of Infectious Diseases, 123, 67-73.
Hallqvist, L., and Lindgren, S. (1975). Gonorrhoea of the throat at a venereological clinic. Incidence and results of treatment. British Journal of Venereal Diseases, 51, 395-397.

Jaffe, H. W., Biddle, J. W., Thornsberry, C., Johnson, R. E., Kaufman, R. E., Reynolds, G. H., and Wiesner, P. J. (1976). National gonorrhea therapy monitoring study. In vitro antibiotic susceptibility and its correlation with treatment results. New England Journal of Medicine, 294, 5-9.

Knapp, J. S., and Holmes, K. K. (1975). Disseminated gonococcal infections caused by Neisseria gonorrhoeae with unique nutritional requirements. Journal of Infectious Diseases, 132, 204-208.

Knights, H. T. (1972). Meningococcal meningitis in New Zealand with special reference to carrier rates in military trainees. New Zealand Medical Journal, 76, 16-22.

Martin, J. E., and Lester, A. (1971). Transgrow a medium for transport and growth of Neisseria gonorrhoeae and Neisseria meningitidis. Health Services and Mental Health Administration Health Reports, 86, 30-33.

Melton, L. J., Edwards, E. A., and Devine, L. F. (1977). Differences between sexes in the nasopharyngeal carriage of Neisseria meningitidis. American Journal of Epidemiology, 106, 215-221.

Newnham, W. A., Walker, W. R., and Fogarty, P. (1975). Faucial gonorrhoea. Medical Journal of Australia, 2, 470-472.

Noble, W. C. (1974). Carriage of Staphylococcus aureus and betahemolytic streptococci in relation to race. Acta dermatovenereologica, 54, 403-405.

Noble, R. C., Kirk, N. M., Slagel, W. A., Vance, B. J., and G. W. Somes. (1977). Recidivism among patients with gonococcal infection presenting to a venereal disease clinic. Sexually Transmitted Disease, 4, 39-43.

Odegaard, K., and Gundersen, T. (1973). Gonococcal pharyngeal infection. British Journal of Venereal Disease, 49, 350-352.

Owen, R. L., and Hill, J. L. (1972). Rectal and pharyngeal gonorrhea in homosexual men. Journal of American Medical Association, 220, 1315-1318.

Pariser, H. (1972). Asymptomatic gonorrhea. Medical Clinics of North America, 56, 1127-1132.

Rodin, P., Monteiro, G. E., and Scrimgeour, G. (1972). Gonococcal pharyngitis. British Journal of Venereal Diseases, 48, 182-183.

Shahidullah, M. (1976). Pharyngeal gonorrhoea in homosexuals. British Journal of Venereal Diseases, 52, 168-169.

Steers, E. E., Foltz, L., and Graves, B. S. (1959). An inoccda replicating apparatus for routine testing of bacterial susceptibility to antiobiotics. Antibiotic Agents and Chemotherapy (Washington, D.C.), 9, 307-311.

Stolz, E., and Schuller, J. (1974). Gonococcal oro- and naso-pharyngeal infection. British Journal of Venereal Diseases, 50, 104-108.

Stutz, D. R., Spence, M. R., and Duangmani, C. (1976). Oropharyngeal gonorrhea during pregnancy. Journal of the American Venereal Disease Association, 3, 65-67.

Wallin, J. (1974). Gonorrhoea in 1972. A 1-year study of patients attending the VD unit in Uppsala. British Journal of Venereal Diseases, 51, 41-47.

Wiesner, P. J., Tronca, E., Bonin, P., Pedersen, A. H. B., and Holmes, K. K. (1973). Clinical spectrum of pharyngeal gonococcal infection. New England Journal of Medicine, 288, 181-185.

Willcox, R. R., Spencer, R. C., and Ison, C. (1977). Which Neisseria? British Journal of Venereal Diseases, 53, 394-397. 